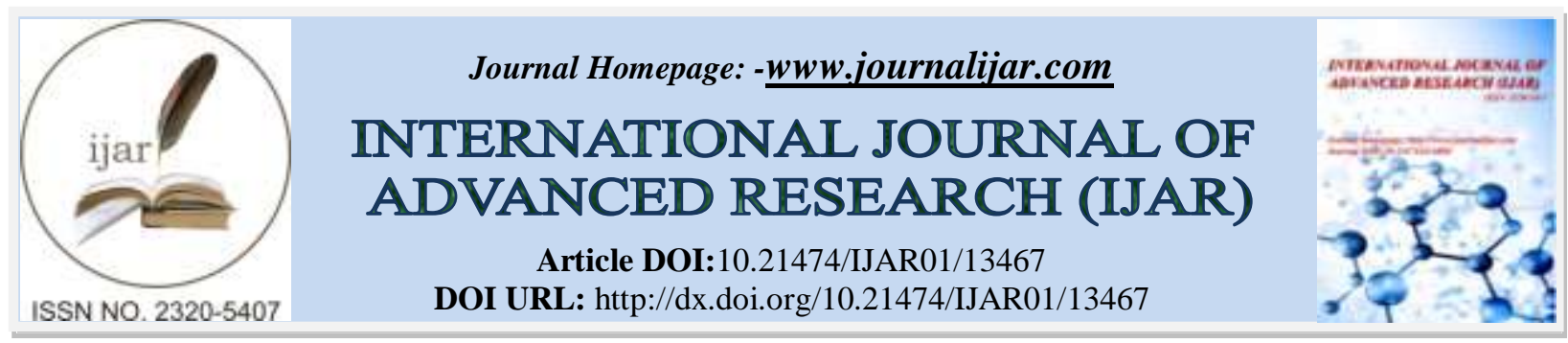

RESEARCH ARTICLE

\title{
A CLINICAL STUDY ON THE PROPHYLACTIC EFFECT OF VIRECHANA IN PRIMARY DYSMENORRHOEA
}

\author{
Dr. Ambili Krishna, Dr. Vinod Kumar and Dr. A.S. Laila \\ Department of Panchakarma, Government Ayurveda College, Trivandrum, Kerala India.
}

\section{Manuscript Info}

...........................

Manuscript History

Received: 28 July 2021

Final Accepted: 31 August 2021

Published: September 2021

Key words: -

Primary Dysmenorrhoea, Virechana,

Sukumaraghritha, Erandataila,

Udavartha

\section{Abstract}

Primary dysmenorrhoea is the most common gynaecological disease in menstruating women. It is a symptom complex with cramping lower abdominal pain radiating to the back and legs often accompanied by gastro intestinal and neurological symptoms as well as general malaise. In conventional system of medicine there is no permanent cure for primary dysmenorrhoea. In order to find out a permanent remedy for preventing the recurrence of primary dysmenorrhoea and to evaluate the effect of virechana in reducing the symptoms of primary dysmenorrhoea, this particular study has been under taken. In Ayurveda gynaecological pathologies are explained under the heading of yonirogas. Clinical features of primary dysmenorrhoea are having similiarities with that of udavartha yoni roga. Apanavatavaigunya is the main causative factor for udavartha yoni roga. In the treatment principle of apanavatavaigunyasnigdhavirechana is indicated. An Interventional type of Quasi Experimental study that is before and after study without control was conducted in Govt Ayurveda College Panchakarma Hospital, Poojapura and Govt Ayurveda College Hospital Thiruvanathapuram. One group of thirty patients fulfilling the inclusion criteria and diagnostic criteria were recruited for the study. Intervention administered were rookshana with takra, snehapana with sukumaraghritha, sarvangaabhyanga and avagahasweda with vataharapatra and virechana was done using sukumaraerandamThaila followed by samsarjanakrama based on suddhi obtained after virechana. Subjective parameters were assessed before and after treatment for three consecutive cycles. Pain the major parameter was recorded as per visual analogue scale and associated symptoms using verbal descriptive scale. Pain and associated symptoms were reduced immediately after the treatment which showed treatment was effective in pacifying the disease. Moreover, in the consecutive follow ups symptoms got reduced remarkably which showed treatment had sustained and progressive effectiveness in reducing the symptoms of disease and on statistical evaluation ' $p$ ' value was found to be highly significant.

Copy Right, IJAR, 2021,. All rights reserved. 


\section{Introduction:-}

Ayurveda emphasizes that the purity and normalcy in structure and function of four factors essential for conceiving a healthy child. They are ritu (Fertile period during which the conception occurs that is ovulation), kshethra (Place of conception that is uterus), ambu (Proper nourishing elements) and beeja (Healthy sperm and ovum). Normal menstruation is the important aspect of feminity and is an index of reproductive health of the woman. Arthavanishkramana is the function of apanavata and it occurs every month without pain. When apanavatavaigunya occurs its function becomes abnormal, then menstruation becomes painful. Such condition is referred to as udavartha which is one among the twenty yonirogas.

In udavartha, vegodavarthana leading to apanavatavaigunya causes arthavavahasrothodushti as sanga and vimargagamana. It results in prathilomagathi of vayu along with rajas, is the underlying pathology. Hence the treatment aims at vatanulomana and garbhasayasodhana.

The classical feature of udavarthayonivyapath is pain, and on analyzing the pathogenesis and clinical features of udavartha it can be correlated with the menstrual disorder primary dysmenorrhoea.

Primary dysmenorrhoea is defined as severe cramping pain in the lower abdomen which is radiating to the back of the legs and low back occurring few hours before, with or few hours after the onset of menstrual bleeding, persisting throughout the first twelve to seventy-two hours without any identifiable pelvic pathology and with associated symptoms such as nausea, anorexia, constipation, fatigue, giddiness, headache and shock. This is the most common gynaecological problem in menstruating women. Reported prevalence rates are as high as $90 \%$. In several longitudinal studies of young women with primary dysmenorrhoea, rates of absenteeism ranged from 34\%-50\% and accounted for 600 million lost work hours and two billion dollars in lost productivity annually.

\section{Need and significance of the study}

Health of a nation mainly depends upon the health of the women. Since primary dysmenorrhoea have substantial effect on health related quality of life and general well being of women, which is also psychologically taxing and debilitating for them, condition needs to be tackled with utmost importance. The treatment protocol should aim at the prevention of recurrence of the above disease and to bestow her with good reproductive power and healthy well being.

In Ayurvedic classics while explaining the general treatment of yonirogas, all Acharyas signifies the role of panchakarma in mild form (ie five therapeutic procedures that brings about homeostasis by way of evacuation of accumulated morbid doshas) before administering samana medicines. Virechana is the only panchakarma indicated for all yonirogas. Virechana though mainly pittasamana therapy, it eventually does vatanulomana and best suited therapy for adhobhagarogas. Virechana karma enhances the reproductive power and it has longlasting effect in reversing the disease pathology. As apanavatavaigunya occurs in udavartha, snehavirechana is indicated.

\section{Aims and Objectives:-}

To assess the efficacy of virechana in reducing the symptoms of primary dysmenorrhoea

To assess the prolonged effect of virechana in preventing the recurrence of primary dysmenorrhoea

\section{Methodology:-}

\section{Source of data and method of collection}

Patient of primary dysmenorrhoea selected from OPD and IPD of Government Ayurveda College Hospital Thiruvananthapuram and Government Ayurveda College Panchakarma Hospital, Poojapura.

30 patients were selected who satisfy the classical symptoms of primary dysmenorrhoea keeping the inclusion and exclusion criteria in consideration. Necessary investigations were carried out and their details were recorded in a special case proforma.

\section{Inclusion Criteria}

Patients with primary dysmenorrhoea having moderate \& severe degree of pain without any evident pelvic pathology confirmed by USG scan Pelvis. 
Age group 18-35 yrs.

Patients indicated for virechana.

Patients with written informed consent.

\section{Exclusion Criteria}

Patients with secondary dysmenorrhoea

Patient not willing for the study

Patients with structural abnormality of reproductive system.

Patients with severe systemic diseases.

\section{Research design}

As the study was interventional type of Quasi experimental study that is before and after study without control. Thirty patients fulfilling the inclusion and diagnostic criteria were recruited for the study. This was a base-line control study in which subject status on therapy is compared with status before therapy have no external and internal control and thus an uncontrolled study. Patients were subjected to detailed evaluation for three consecutive menstrual cycles (in the bleeding phase) before the treatment by history taking.

\section{Intervention}

1. Rookshana Takrapana was advised until the attainment of samyakrookshanalakshanas.

2. Snehapana with sukumaraghritha until the attainment of samyaksnigdha lakshanas was done.

3. Abhyangam and avagahaswedawas done as per classics for three days (in the vishramakala before virechana). During the visramakala, person was advised to follow diet comprising of snigdha, ushna, drava, mamsarasa, yoosha, amla rasa and kaphavardhakaahara was strictly avoided to maintain mandakapha state in the body.

4. Virechana with SukumaraerandaThaila was done on the $4^{\text {th }}$ day after snehapana.

5. Samsarjanakrama with Peya, Vilepi, mudgayoosha and mamsarasawas advised based on suddhi observed.

\section{Duration of study}

The study was cFrooarried out within 18 months after submitting the proforma. Total duration of intervention was 11-15 days starting after the bleeding phase of menstruation extending upto secretory phase of menstrual cycle.

\section{Observation and assessment}

Patients were assessed with subjective parameters at following stages based upon the assessment criteria.

1. 1st assessment:Three consecutive menstrual cycles (in the bleeding phase) before the treatment by history taking.

2. 2nd assessment:In the next menstrual cycle (bleeding phase) coming immediately after the treatment

3. 3rd and 4th assessment: Consecutive two cycles (bleeding phase) after second assessment which constitutes follow up period

\section{Statistical analysis}

The efficacy of treatment in this study was analyzed by calculating the mean, standard deviation of the parameters as well as ' $t$ ' and ' $\mathrm{p}$ ' value using 'paired t-test' at before treatment, after treatment and after follow up. Diagrams and charts were also drawn to signify the important findings. The software named S.P.S.S was used for statistical calculations.

Pain Immediate effect of treatment on lower abdominal pain

\begin{tabular}{|l|l|l|l|l|l|l|l|}
\hline Stage & Mean & N & $\begin{array}{l}\text { Standard } \\
\text { deviation }\end{array}$ & Pair & $\begin{array}{l}\text { Mean } \\
\text { difference }\end{array}$ & Paired t & p-value \\
\hline BT & 8.2433 & 30 & 1.61580 & & & & \\
\hline AT & 6.8333 & 30 & 1.55549 & BT \&AT & 1.4100 & 16.131 & $<0.001$ \\
\hline FU-I & 4.6000 & 30 & 1.86806 & BT \& FU-I & 3.6433 & 14.250 & $<0.001$ \\
\hline FU-II & 2.8333 & 30 & 2.30567 & BT \& FU -II & 5.4100 & 14.456 & $<0.001$ \\
\hline
\end{tabular}

In the case of lower abdominal pain, before treatment mean was 8.2433 which was reduced to 6.8333 after treatment, with $17.10 \%$ of relief in pain. On statistical evaluation p-value is highly significant with paired t-value 16.131 showing the treatment is effective in reducing pain. 
The mean value of pain in first and second follow up are 4.6000 and 2.8333 respectively which on comparison with before treatment mean 8.2433 showed treatment is more effective in consecutive follow up periods with $44.19 \%$ and $65.62 \%$ of relief respectively which on statistical analysis, $\mathrm{p}$-value is highly significant with paired $\mathrm{t}$-value 14.250 and 14.456 respectively showing the treatment effect is progressive.

Prolonged effect of treatment on lower abdominal pain

\begin{tabular}{|l|l|l|l|l|l|l|l|}
\hline Stage & Mean & N & $\begin{array}{l}\text { Standard } \\
\text { deviation }\end{array}$ & Pair & $\begin{array}{l}\text { Mean } \\
\text { difference }\end{array}$ & Paired t & p-value \\
\hline AT & 6.8333 & 30 & 1.55549 & & & & \\
\hline FU-I & 4.6000 & 30 & 1.86806 & AT \& FU-I & 2.2333 & 9.571 & $<0.001$ \\
\hline FU-II & 2.8333 & 30 & 2.30567 & AT \& FU -II & 4.000 & 11.050 & $<0.001$ \\
\hline
\end{tabular}

Comparing after treatment mean (6.8333) with mean after first follow up (4.6000) and second follow up (2.8333) showed treatment had sustained and progressive effectiveness in reducing pain than immediate effect (AT) with $32.68 \%$ and $58.53 \%$ of relief. On statistical evaluation p-value is highly significant with paired t-value 9.571 and 11.050 respectively.

Presence of Clots

Immediate effect of treatment on clots

\begin{tabular}{|l|l|l|l|l|l|l|l|}
\hline Stage & Mean & N & $\begin{array}{l}\text { Standard } \\
\text { deviation }\end{array}$ & Pair & $\begin{array}{l}\text { Mean } \\
\text { difference }\end{array}$ & Paired t & p-value \\
\hline BT & 2.38 & 24 & 0.576 & & & & \\
\hline AT & 1.58 & 24 & 0.504 & BT \&AT & 0.792 & 9.349 & $<0.001$ \\
\hline FU-I & 1.21 & 24 & 0.721 & BT \& FU-I & 1.167 & 8.972 & $<0.001$ \\
\hline FU-II & 1.08 & 24 & 0.830 & BT \& FU -II & 1.292 & 8.430 & $<0.001$ \\
\hline
\end{tabular}

In the case of presence of clots, before treatment, mean was 2.38 which were reduced to 1.58 after treatment with $33.61 \%$ of relief in presence of clots. On statistical evaluation p-value is highly significant with paired t-value 9.349 showing the treatment is effective in reducing presence of clots.

The mean value of presence of clots in first and second follow up are 1.21 and 1.08 respectively which on comparison with before treatment mean 2.38 showed treatment is more effective in consecutive follow up periods with $49.16 \%$ and $54.62 \%$ of relief respectively which on statistical analysis, p-value is highly significant with paired t-value 8.972 and 8.430 respectively showing the treatment effect is progressive.

Prolonged effect of treatment on clots

\begin{tabular}{|l|l|l|l|l|l|l|l|}
\hline Stage & Mean & N & $\begin{array}{l}\text { Standard } \\
\text { deviation }\end{array}$ & Pair & $\begin{array}{l}\text { Mean } \\
\text { difference }\end{array}$ & Paired t & p-value \\
\hline AT & 1.58 & 24 & 0.504 & & & & \\
\hline FU-I & 1.21 & 24 & 0.721 & AT \& FU-I & 0.375 & 2.584 & $<0.05$ \\
\hline FU-II & 1.08 & 24 & 0.830 & AT \& FU -II & 0.500 & 3.140 & $<0.01$ \\
\hline
\end{tabular}

Comparing after treatment mean (1.58) with mean after first follow up (1.21) and second follow up (1.08) showed treatment had sustained and progressive effectiveness in reducing presence of clots than immediate effect (AT) with $23.42 \%$ and $31.65 \%$ of relief. On statistical evaluation p-value is significant with paired t-value 2.584 and 3.140 respectively.

Nausea

Immediate effect of treatment on nausea

\begin{tabular}{|l|l|l|l|l|l|l|l|}
\hline Stage & Mean & N & $\begin{array}{l}\text { Standard } \\
\text { deviation }\end{array}$ & Pair & $\begin{array}{l}\text { Mean } \\
\text { difference }\end{array}$ & Paired t & p-value \\
\hline BT & 2.20 & 25 & 0.500 & & & & \\
\hline AT & 1.52 & 25 & 0.510 & BT \&AT & 0.680 & 7.141 & $<0.001$ \\
\hline FU-I & 1.08 & 25 & 0.400 & BT \& FU-I & 1.120 & 9.333 & $<0.001$ \\
\hline FU-II & 1.04 & 25 & 0.455 & BT \& FU -II & 1.160 & 9.287 & $<0.001$ \\
\hline
\end{tabular}


In the case of nausea, before treatment mean was 2.20 which was reduced to 1.52 after treatment with $30.91 \%$ of relief in nausea. On statistical evaluation p-value is highly significant with paired t-value 7.141 showing the treatment is effective in reducing nausea.

The mean value of nausea in first and second follow up are 1.08 and 1.04 respectively which on comparison with before treatment mean 2.20 showed treatment is more effective in consecutive follow up periods with $50.91 \%$ and $52.73 \%$ of relief respectively which on statistical analysis, p-value is highly significant with paired t-value 9.333 and 9.287 respectively showing the treatment effect is progressive.

Prolonged effect of treatment on nausea

\begin{tabular}{|l|l|l|l|l|l|l|l|}
\hline Stage & Mean & N & $\begin{array}{l}\text { Standard } \\
\text { deviation }\end{array}$ & Pair & $\begin{array}{l}\text { Mean } \\
\text { difference }\end{array}$ & Paired t & p-value \\
\hline AT & 1.52 & 25 & 0.510 & & & & \\
\hline FU-I & 1.08 & 25 & 0.400 & AT \& FU-I & 0.440 & 3.773 & $<0.001$ \\
\hline FU-II & 1.04 & 25 & 0.455 & AT \& FU -II & 0.480 & 4.096 & $<0.001$ \\
\hline
\end{tabular}

Comparing after treatment mean (1.52) with mean after first follow up (1.08) and second follow up (1.04) showed treatment had sustained and progressive effectiveness in reducing nausea than immediate effect (AT) with $28.95 \%$ and $31.58 \%$ of relief. On statistical evaluation p-value is highly significant with paired t-value 3.773 and 4.096 respectively.

\section{Constipation}

Immediate effect of treatment on constipation

\begin{tabular}{|l|l|l|l|l|l|l|l|}
\hline Stage & Mean & N & $\begin{array}{l}\text { Standard } \\
\text { deviation }\end{array}$ & Pair & $\begin{array}{l}\text { Mean } \\
\text { difference }\end{array}$ & Paired t & p-value \\
\hline BT & 2.46 & 26 & 0.508 & & & & \\
\hline AT & 1.58 & 26 & 0.504 & BT \&AT & 0.885 & 10.455 & $<0.001$ \\
\hline FU-I & 1.23 & 26 & 0.710 & BT \& FU-I & 1.231 & 9.631 & $<0.001$ \\
\hline FU-II & 0.85 & 26 & 0.925 & BT \& FU -II & 1.615 & 9.666 & $<0.001$ \\
\hline
\end{tabular}

In the case of constipation, before treatment mean was 2.46 which was reduced to 1.58 after treatment, with $35.77 \%$ of relief in constipation. On statistical evaluation p-value is highly significant with paired t-value 10.455 showing the treatment is effective in reducing constipation.

The mean value of constipation in first and second follow up are 1.23 and 0.85 respectively which on comparison with before treatment mean 2.46 showed treatment is more effective in consecutive follow up periods with $50 \%$ and $65.45 \%$ of relief respectively which on statistical analysis, p-value is highly significant with paired t-value 9.631 and 9.666 respectively showing the treatment effect is progressive.

Prolonged effect of treatment on constipation

\begin{tabular}{|l|l|l|l|l|l|l|l|}
\hline Stage & Mean & N & $\begin{array}{l}\text { Standard } \\
\text { deviation }\end{array}$ & Pair & $\begin{array}{l}\text { Mean } \\
\text { difference }\end{array}$ & Paired t & p-value \\
\hline AT & 1.58 & 26 & 0.504 & & & & \\
\hline FU-I & 1.23 & 26 & 0.710 & AT \& FU-I & 0.346 & 2.560 & $<0.05$ \\
\hline FU-II & 0.85 & 26 & 0.925 & AT \& FU -II & 0.731 & 4.503 & $<0.001$ \\
\hline
\end{tabular}

Comparing after treatment mean (1.58) with mean after first follow up (1.23) and second follow up (0.85) showed treatment had sustained and progressive effectiveness in reducing constipation than immediate effect (AT) with $22.15 \%$ and $46.20 \%$ of relief. On statistical evaluation p-value is significant with paired t-value 2.560 after first follow up and it is highly significant with paired t-value 4.503 after second follow up.

\section{Discussion:-}

Dysperistalsis and hyperactivity of the uterine junctional zone are the important mechanisms of primary dysmenorrhoea. The imbalance of autonomic nervous system is another acceptable theory behind abnormal uterine action. 
Inadequate liquefaction of menstrual clots, hormonal imbalance especially in the levels of progesterone and prostaglandins can be included under pradushtarthava. Progesterone has a thermogenic effect as it increases the basal body temperature by $0.8^{0}$ to $1^{0} \mathrm{~F}$ in the secretory phase of menstrual cycle. According to Ayurveda the secretory phase is the rituvyatheethakala. This phase is dominated by pitta, because the arthava at this phase is of agneya character. In this phase dominated by pitta, derangement occurs in the female reproductive physiology leading to the excess production of prostaglandins. Though vata is the main dosha involved in udavartha and role of hormonal imbalance (pradushtaarthava) can be attributed to associated pitta dushti. Thus the role of vata and pitta can be explained in the pathogenesis of udavartha where vata plays a major role with association of pitta greatly.

Virechana is the only panchakarma indicated for all yonirogas. Virechana is mainly pitta samana therapy, it eventually does Vatanulomana and best suited therapy for adhobhagarogas. Role of vata and pitta in pathogenesis of udavartha is well explained in the above discussion. So virechana is most suited sodhana therapy considering the sthana of roga and pathogenesis of the disease. Virechana karma enhances the reproductive power and it may have long lasting effects in reversing the disease pathology.

SukumaraerandaThaila is castor oil processed with drugs of sukumaraghritha mentioned in vriddhichikitsa in Ashtangahridaya.ErandaThaila is agryadravya for virechana according to Ayurvedic classics (CharakasamhithaSoothrasthana 13/2). Due to ushna, sara, sookshma properties it has penetrating capacity to enter the sookshmasrothas, clenses the vagina and cures the pain of low back and genital region. Thus the ingredients of sukumaraghritha which has site specific (garbhasaya) as well as disease specific action (Yonisoolahara) which when processed with erandathaila its potency and disease alleviating nature is enhanced.

Among the theories explaining the causes of pain, the role of hormones especially progesterone, prostaglandins, neuritis of presacral nerve suggest the role of pitta. In addition, according to ayurveda the secretory phase of menstrual cycle is described as rithuvyatheethakala. This phase is dominated by pitta because the arthava at this phase is of agneya character. In this phase dominated by pitta, derangement in female reproductive physiology resulting in excess production of prostaglandins leading to manifestation of pain and associated symptoms in dysmenorrhoea. Thus the role of Vata and pitta is well established in the pathogenesis of primary dysmenorrhoea. In samanyaupakrama of Vatadosha [AshtangaHridayaSoothrasthana] and samanya yoni rogachikitsa, sneha, sweda and mridusodhana is explained as prime and foremost treatment. Sukumaraghritha and sukumaraerandaThaila was used for snehapana and virechana respectively, in which the major ingredients are having madhura rasa, ushnaveerya and snigdhaguna and hence these can normalise the gathi of Vata. Moreover, many of the ingredients are tridoshahara, anulomana, sothahara, vedanasthapana, garbhasayasodhana and rasayana. Snehapana with sukumara ghritha provides the above desired effects especially to garbhasaya and adhonabhipradesa due to the site specific action of the compound preparation.

Virechana acts upon srotovaigunya such as sanga and vimargagamana occurred in arthavavahasrothas and overcomes the obstruction in gathi of rajas and helps in normalising the menstrual flow due to its srothosodhana and Vata anulomanaproperty. In the present study virechana was done in rituvyatheethakala which is dominated by pitta where arthava is agneya in character. In modern parlance this stage is secretory phase of menstrual cycle where there is excess production of prostaglandins leading to manifestation of pain and associated symptoms in primary dysmenorrhoea. Thus virechana done at this stage of menstrual cycle may decrease the production of prostaglandins thereby reversing the pathology of disease and ultimately leading to the cure of the disease and its prevention in long run. It can also be attributed that virechana has a specific action at hormonal level. Virechana by its systemic action may also reduce the associated gastrointestinal and neurological symptoms.

\section{Conclusion:-}

Primary dysmenorrhoea is the most common gynaecological condition which interfere the working capacity of women even producing psychological disturbances. Improper arthavacharya, vegadharana, sedentary lifestyle, positive family history and low fibre diet plays a major role in the onset of the disease. Virechana with its vatanulomanasrothorodhanivarana and adhobhagadoshaharathwaaction proved to be better treatment therapy for primary dysmenorrhoea. Virechana with sukumaraerandathaila employed in secretory phase of menstrual cycle that is one week before menstruation is very much beneficial in reducing symptoms of primary dysmenorrhoea. The study revealed that treatment had sustained and progressive effect in reducing the symptoms of the disease in consecutive cycles which showed the prophylactic action of the virechana. 


\section{References:-}

1. AshtangaHridaya, commentary by Arunadatta and Hemadri, edited by HarishastriParadkar, published by Krishnadas Academy, 1995 edtn.

2. AshtangaSangraha, English translation by Prof. K.R. Srikanta Murthy, ChaukambhaOrientalia, Varanasi, 2000 edtn

3. Bhava Mishra, "Bhavaprakash", translation by prof. K.R. Srikantha Murthy, $1^{\text {st }}$ edition, Varanasi, Krishnadas Academy, Oriental Publishers and distributors, 1998.

4. Bhela - BhelaSamhita, edited by Sharma P.V. Published by ChaukhambhaVishwabharathi Oriental Publishers and distributors, Varanasi, 1st edition 2000.

5. Chakrapanidatta - Ayurveda Deepika commentary on CharakaSamhitha, ChoukhambhaOrientalia

6. Indian Medicinal Plants, edited by P.K. Warrier, V.P.K. Nambiar and C.RRamanKutty 1st edition, reprinted in 2002, Orient Longman Pvt. Ltd

7. AyurvedeeyaPrasuthiThantraevamStriroga , PremvathyTivariChoukhambhaOrientalia Varanasi 2000

8. Ayurvedic Concepts in Gynacology by Nirmala .G.Joshi

9. Text book of gynaecology -D.C.Dutta $-4^{\text {th }}$ edition

10. Principles and practice of obstetrics and gynaecology for post graduates,Federation of Obstetrics and gynaecological societies of india

11. Gynaecolgy for post graduates and practitioners, B.I. Churchil, Livingstone Pvt Ltd.New Delhi

12. Shaws Text book of Gynaecology-13 ${ }^{\text {th }}$ Edition, Hawkins and Bourne

13. British Medical Journal - Diagnosis and Management of dysmenorrhoea, Michelle Proctor andCynthia Farquhar

14. Dysmenorrhoea - From Wiki Pedia, the free encyclopedia

15. Jeffcoate's principles of gynaecology,

16. Gynaecology Third Edition, Edited by Robert.W.Shaw,W.PatrickSoutter,Stuart.L.Stanton. 